\title{
THE ROLE OF FAN BENEFITS IN SHAPING RESPONSES TO SPONSORSHIP ACTIVATION
}

\author{
Jan Dreisbach \\ Research Fellow \\ Technische Universität Braunschweig \\ Services Management Research Group \\ Mühlenpfordtstraße 23 \\ 38106 Braunschweig, Germany \\ j.dreisbach@tu-braunschweig.de
}

\author{
David M. Woisetschläger* \\ Professor of Services Management \\ Technische Universität Braunschweig \\ Services Management Research Group \\ Mühlenpfordtstraße 23 \\ 38106 Braunschweig, Germany \\ d.woisetschlaeger@tu-braunschweig.de \\ +49-531-391-63120 \\ Christof Backhaus \\ Professor of Marketing \\ Aston Business School \\ Marketing and Strategy Group \\ Aston Triangle \\ Birmingham, B4 7ET, United Kingdom \\ c.backhaus@aston.ac.uk \\ T. Bettina Cornwell \\ Edwin E. \& June Woldt Cone Professor of Marketing \\ Eugene, OR 97403-1208, USA \\ tbc@uoregon.edu
}

Department of Marketing, Lundquist College of Business, University of Oregon,

*Corresponding author

Paper accepted for publication in Journal of Business Research. 


\begin{abstract}
As sponsorship in sports, arts and entertainment has grown, so have the myriad ways to activate partnerships. This study investigates the mechanisms through which sales-oriented activation campaigns affect consumer evaluations. Based on a benefit typology derived from real-world sponsorship activations, a conceptual framework is developed that links financial, symbolic and social benefit dimensions to consumer inferred activation motives and subsequent sponsor outcomes. An experimental field study of 1,356 soccer fans employing three activation scenarios and a control group tests the framework. Results of a structural equation model show that altruistic motives are key in determining sponsorship outcomes, and that activation campaigns designed for symbolic or social benefits are most effective in inducing inference of altruistic motives.
\end{abstract}

Keywords: sport; leverage; activation; motives; financial incentives; sponsorship fit 


\section{THE ROLE OF FAN BENEFITS IN SHAPING RESPONSES TO SPONSORSHIP ACTIVATION}

\section{Introduction}

With expenditures of US\$62.7 billion worldwide in 2017, sponsorship has become well established as a marketing communications strategy (International Event Group (IEG) 2018). The rise of sponsorship has become particularly evident in the last two decades. Total expenditures have quadrupled - with the highest growth in sports, compared to other property types such as arts, causes and entertainment (IEG 2018).

Advertising intensity in traditional media markets has been identified as one reason for the rise of sponsorship (e.g., Meenaghan 1998; Roy and Cornwell 2004), but now this same intensity is found in sponsorship. Particularly in sports, and in prominent platforms such as top international and national leagues, sponsors compete for the communication opportunities provided by rights holders. In the German Soccer Bundesliga's 2017/2018 season, for example, 380 different sponsors sought TV audience attention, resulting in an average of 21 sponsors for each of the 18 clubs (Sponsors 2017). Consequently, both industry experts and sports marketing researchers describe communication landscapes in the context of sports as increasingly cluttered (Cornwell, Weeks, and Roy 2005; Meenaghan 1998).

Given that sponsorship is now cluttered and that the attention capacity of sports audiences is limited (Breuer and Rumpf 2015), mere logo exposure during a sporting event is not enough to ensure sponsor success, if it ever was. Spending by brand and corporate sponsors beyond the sponsorship deal is utilized to engage consumers with the brand in conjunction with their relationship to the sponsored property, the sport, art or entertainment. This collateral spending, 
also known as sponsorship leveraging has therefore become a sine-qua-non in reaching intended communication objectives (Cornwell et al. 2005; Donlan and Crowther 2014).

Whereas leveraging includes all collateral marketing communications related to the sponsorship investment, sponsorship activation relates to communications that encourage interaction with the sponsor (Weeks, Cornwell, and Drennan 2008). Sponsorship activation goes beyond one-way basic advertising and promotion to two-way communication and even advanced forms such as complex real-time campaigns that draw on consumer geolocation and local weather conditions (Activative 2017). Frequently, sponsors implement sales-oriented activation campaigns that are directly related to a sponsor's product or service offering. For example, financial services provider Western Union activated their shirt-sleeve deal with Liverpool FC by a short-term money transfer promotion offered to Liverpool fans in selected countries (Western Union 2017). Hypovereinsbank, a European bank headquartered in Munich, has established a whole range of customized products and exclusive offerings for FC Bayern Munich fans to activate their partnership with the Bavarian club. Customers of their FC Bayern credit card could, for example, apply for an exclusive home match ticket, even for matches already ostensibly sold out (Hypovereinsbank 2017).

While activation campaigns should seemingly support a sponsor's strategic objectives, there is a major caveat to be considered: Sponsorship audiences are becoming more sensitive to commercial activities, and, in particular, to sponsor's calculative motivations (Meenaghan 2001; Woisetschläger, Backhaus, and Cornwell 2017). A representative study in the context of soccer in Germany found that more than $75 \%$ of respondents believe sponsors in the German Bundesliga initiate activation measures for egoistic motives (Woisetschläger, Backhaus, Dreisbach, and Schnöring 2014). If not carefully designed and implemented, activation 
campaigns negatively affect the "halo of goodwill" (Meenaghan 2001, p. 101) in which sponsorship is generally seen, thereby counteracting the intended positive sponsorship effects. Consequently, sponsors and sponsees find it difficult to develop and deploy sponsorship activations that do not smack overly of brand self-promotion. For example, a German mobile phone service provider and former sponsor of FC St. Pauli installed an LED display in their stadium, to which visitors could send fee-based SMS messages. This activation approach triggered a petition signed by 3,000 St. Pauli fans opposing the "sell out" of the club's identity (Glindmeier 2011).

Given this tension between the need for sponsorship activation to communicate with potential consumers and audience sensitivity to commercial involvement in sports, sponsors have begun to link activations with benefits that accrue to the sponsorship context (e.g., sport), the particular sponsee (e.g., a team) or a beneficiary (e.g., a charity associated with the context or sponsee). While it has been acknowledged that learning about which sponsorship activation works best usually occurs by "trial and error" (Kuzma, Shanklin, and McCally 1993), the academic literature lacks a framework that conceptualizes fundamental activation design characteristics, implications for inference making and important sponsor outcomes. Prior research shows that sponsorship-linked communication in general is effective in raising sponsor outcomes (Mazodier and Quester 2014). Of particular relevance for this study are downstream effects of alternative sales-oriented sponsorship activation campaigns on inferred activation motives, sponsorship fit, as well as attitude and loyalty towards the sponsor. These related variables reflect an effect chain that has not been examined. This lack of knowledge is particularly surprising given the monetary scale of sponsorship activation. A survey of property decision-makers finds that each $\$ 1$ a sponsor spends on rights fees, the contract that establishes 
the partnership, implies another $\$ 2.20$ to activate the sponsorship (IEG 2016). Brands must respond to the new balancing act - to communicate on point for the brand but at the same time participate in a community critical of foisted commercialization.

Against this background, the current work investigates the mechanisms through which alternative campaign design strategies affect consumer evaluations of sales-oriented activation campaigns. In particular, the current research examines activation campaigns that offer a benefit to fans for their brand-related behaviors. Based on a benefit typology derived from 68 real-world sponsorship activation campaigns, the study develops a conceptual framework that links financial, symbolic and social benefit dimensions to consumer inferred campaign motives and subsequent sponsor outcomes. An experimental field study ( $\mathrm{n}=1,356$ fans) with a betweensubjects manipulation of financial, symbolic and social benefits tests the conceptual model.

The remainder of the paper is organized as follows. The next paragraph outlines the conceptual background in the area of sponsorship activation, and derives the set of hypotheses to be tested. Subsequent sections describe methods and data. The concluding sections present findings, offer implications for theory as well as practice, and suggest future research opportunities.

\section{Conceptual Background}

Campaign-related Factors as Antecedents to Consumer Responses to Sponsorship Activation

Borrowed from work in the areas of sponsorship and corporate social responsibility (Cornwell et al. 2005; Du, Bhattacharya, and Sen 2010), this study is based on a stimulus-organism-response (SOR) model of sponsorship activation. Figure 1 depicts the conceptual model, showing that activation campaign-related factors shape inferences audiences make regarding a sponsor's 
underlying campaign motivations. These inferences, in turn, impact perceived sponsorship fit, which subsequently influences sponsor brand attitude and loyalty. Context and partner-related factors help explain how effectively activation campaigns generate sponsor outcomes. It should be noted that Figure 1 offers a general model not all of which is examined empirically in the current work.

With regard to the activation campaign-related factors depicted in the left box, key decisions sponsors face include what a campaign entails (campaign content), and how to communicate about it (campaign communication). Important aspects related to campaign content include the general type of the campaign, the reference object chosen in the campaign, and the fit of the campaign with the sponsor, among other aspects. Regarding its reference object, a sponsor's campaign might for example relate directly to the sponsored team, or instead communicate the sponsor's intent to support sports in a broad sense. Here, findings by Grohs et al. (2015) suggest that the latter strategy is advantageous when targeting semi-strongly identified fans in contexts of significant rivalry.

The latter aspect, campaign communication, addresses issues such as by whom, to whom, when, how and via which channels the campaign message is communicated. Past research offers a number of sponsorship specific findings regarding these aspects. Investigating the campaign sender's role, Simmons and Becker-Olsen (2006) show that communicating an activation campaign through the sponsee rather than from the sponsoring brand can mitigate negative effects of a low sponsorship fit. With regard to the targeted audience, results obtained by Bee and Dalakas (2015) show that a print advertisement activation positively influences fan's attitude towards the ad and also purchase intention but for fans of the rival team, effects work in the opposite direction. Also, sponsee-initiated communication does not seem to be more effective 
in the context of rival-team sponsorships (Grohs, Reisinger, and Woisetschläger 2015). Another aspect of campaign communication does seem to hold general value, and that is explaining, or articulating a link between the sponsor and the sponsored. An articulation of sponsorship fit within messages has been shown to positively influence consumer perceptions of the sponsorship, the sponsor brand, and sponsor-event recall (Coppetti, Wentzel, Tomczak, and Henkel 2009; Cornwell, Humphreys, Maguire, Weeks, and Tellegen 2006).

Context-and partner-related factors comprise characteristics of sponsors and sponsees, and contextual boundaries that influence the effectiveness of sponsorship activation. Important sponsor characteristics that may influence sense making of the sponsorship are the reputation of a sponsor as a firm - for instance if it operates in a controversial industry such as tobacco, alcohol or gambling (Crompton 2014). Activation-induced effects may also depend on the extent to which both sponsorship partners express their identities as sport clubs and sponsors (Woisetschläger, Backhaus, and Cornwell 2017). In addition, sponsorship activation could be more effective when sponsees support sponsors in their activation campaign (Farrelly and Quester 2003), and when activation clutter is low (Cornwell and Relyea 2000). Activation effects could be also influenced by contextual boundaries such as differences in audience sensitivity to commercialization (McDaniel and Chalip 2002), property type (Gwinner 1997), and the professional level of the property (Woisetschläger, Backhaus, and Cornwell 2017).

Coming back to the concept of audience benefits, sales oriented activation campaigns frequently offer benefits to fans but the nature of such benefits varies. A product-related promotion (as in case of the Western Union shirt sleeve deal with Liverpool FC) primarily represents a financial benefit for fans, whereas a "meet \& greet" with players organized by a sponsor offers a symbolic benefit for individuals. Social benefits accruing to the community 
represent a third benefit type frequently addressed in activation campaigns. For example, a German brewery, sponsor of Borussia Dortmund, offered financial support for local soccer clubs, helping to renovate stadiums and infrastructure, in return for each crate of beer bought by fans.

The examples, and focused findings outlined do not, however, come together to provide guidance in selecting a particular type of fan benefit relative to another. To begin to understand the types of benefits activation-campaigns offer fans, this study followed a two-step approach. First, an extensive review of consumer benefit and value conceptualizations identified in different literature streams provided a utilitarian (functional/financial), emotional (symbolic) and social (community) benefits schema (e.g., Chandon, Wansink, and Laurent 2000; Green and Peloza 2011; Sheth, Newman, and Gross 1991). Second, primary research conducted to seek correspondence between prior research and this context, classified 68 activation campaigns implemented by sponsors in the German Soccer Bundesliga and revealed that sponsors design their campaigns to entail financial, symbolic and/or social benefits. In particular, financial benefits were offered in $59 \%$ of the campaigns, while $43 \%$ were classified as entailing symbolic and $22 \%$ social benefits. Given the convergence of theoretical categories and empirical evidence, financial, symbolic, and social benefit types are utilized in the subsequent empirical investigation.

\section{Consumer Inference Making and Sponsor Outcomes}

When confronted with sponsorship messages, consumers tend to make assumptions about a sponsor's motives. Consequently, literature in the fields of sponsorship and corporate social sustainability has emphasized role of consumer-inferred motives in shaping consumer perceptions of respective campaigns (e.g., Ellen, Webb, and Mohr 2006; Rifon, Choi, Trimble, 
and Li 2004). When exposed to a sales-oriented activation campaign, the underlying sponsor motives may not be transparent to fans, we therefore suggest that fans draw on design characteristics embedded in an activation campaign to make sense of its goals. Thereby, depending on the nature and communication of the benefits, inference of activation campaignrelated motives is likely to differ. In correspondence with sponsor-sponsee relationships in sports, three motives are of general relevance (Woisetschläger et al. 2017). First, consumers may perceive a sponsor to primarily engage out of self-interest or egoistic motives. Second, brands might relate to a sponsee, the club or their beneficiary, out of altruism or good intentions, expressing their support via a sponsorship. Finally, a sponsorship might reflect pressure from stakeholders or even internal pressure toward normative behavior that can be seen as doing what should be done and thus be associated with normative motives. While normative motives are important in sponsorship, there is only limited evidence with regard to their role in shaping consumer inference making (Woisetschläger et al. 2017). Moreover, sales oriented activations would likely not be based on expected social norms. Thus, this work focuses on altruistic vs. egoistic motives as mediators of the relationship between campaign benefit types and sponsor outcomes. These motivations are depicted in the central box of Figure 1.

In the right box, Figure 1 depicts sponsorship fit, followed by sponsor attitude and sponsor loyalty as sponsor outcomes of activation campaigns. Sponsorship fit refers to the extent to which consumers perceive sponsor and sponsored property as being congruent (Simmons and Becker-Olsen 2006). While sponsorship fit is often times conceptualized as a moderator or mediator in sponsorship research (e.g., Speed and Thompson 2000; Woisetschläger et al. 2017), this model proposes sponsorship fit as an outcome of sponsor activation for two reasons. First, sponsors often intend to influence fit perceptions by means of activation campaigns. Particularly 
in case of sponsors with a low natural fit to properties, perceived fit has been shown to improve as a result of an effective activation (Becker-Olsen and Simmons 2002). Here, effective activations allow consumers to make sense of the partnership by articulating aspects the sponsor and the sponsee have in common. Second, this study conceptualizes sponsorship fit as a consequence of an individual's campaign motive attributions. Sponsorship fit is arguably malleable, and when experiencing and making inferences about a particular activation campaign, fit becomes a dependent variable of interest. This is consistent with empirical findings showing that sponsorship-related communication influences sponsorship fit (Mazodier and Quester 2014).

[Figure 1 here]

\section{Hypotheses Development}

\section{Campaign benefits as antecedents to inferred activation motives and sponsor outcomes}

Given audience sensitivity to commercialization, this study proposes that activations incorporating fan benefits might effectively counterbalance potential negative effects associated with activations that have a sales orientation. In particular, a benefit-based activation campaign could safeguard the sponsorship "halo of goodwill" (Meenaghan 2001, p. 101). But why should fans see sponsors in a different light when an activation campaign entails a benefit?

Social exchange theorists argue that gestures of goodwill or benevolence imply the need to reciprocate and, by doing so, manifest their gratitude (Blau 1964; Gouldner 1960). In the field of relationship marketing, Palmatier et al. (2009) have shown that benefits obtained induce shortterm emotions of gratitude, which subsequently result in reciprocal behaviors and drive objective relational outcomes. Motives that a recipient infers as underlying an act of 'giving' thereby 
influence the recipient's gratitude, with more benevolent (as opposed to ulterior) motives resulting in higher gratitude (Palmatier, Jarvis, Bechkoff, and Kardes 2009). Thus, fans should react more positively to activation campaigns, which incorporate a clear benefit, and infer less calculative sponsor motives. Being given the opportunity to participate in the campaign and, by doing so, receiving a benefit, fans should generally associate altruistic motives as underlying the sponsor's offering. Also, the embedded benefit should result in a need to reciprocate, which manifests in more positively perceived sponsorship fit and sponsor attitude (Kim, Lee, Magnusen, and Kim 2015). Thus:

$H_{1 a 1-c l}:$ (a) Financial, (b) symbolic, and (c) social benefits positively impact inference of altruistic activation motives.

$H_{1 a 2-c 2:}$ (a) Financial, (b) symbolic, and (c) social benefits negatively impact inference of egoistic activation motives.

$H_{2 a-c}:(a)$ Financial, (b) symbolic, and (c) social benefits positively impact sponsorship fit.

\section{The role of inferred campaign motives}

Consumers who perceive that a sponsorship results from emotional attachment to the property, or an altruistic motive, evaluate the sponsoring brand more favorably (Deitz, Myers, and Stafford 2012; Rifon et al. 2004). According to the multiple inference model (MIM) of attribution (Reeder, Vonk, Ronk, Ham, and Lawrence 2004), altruistic motives are by nature "free-choice" (i.e., perceptions are that the sponsor freely chooses to support the club, free from calculative or

egoistic motives). Furthermore, the MIM suggests that free-choice motives result in positive trait attributions, whereas ulterior motives result in negative trait attributions (Reeder et al. 2004). Applying this theory, a campaign approach that induces inference of altruistic activation motives 
should result in more positive attitudinal and behavioral outcomes. In turn, if an activation campaign evokes suspicions of being implemented for calculative (i.e., egoistic) reasons, sponsorship fit and subsequent outcomes should be less positive. These arguments are in line with empirical findings from the relationship marketing as well as the sponsorship literature (Palmatier et al., 2009; Woisetschläger et al. 2017). For example, non-commercial sponsor motives were found to positively affect sponsor attitude, opposed to commercial motives (Na and Kim 2013; Weeks, Cornwell, and Drennan 2008).

The fan experience of receiving a benefit does not directly exert a positive influence on sponsor outcomes. Rather, and in line with the MIM (Reeder et al. 2004), benefits incorporated into an activation campaign trigger a sense-making process, so that consumers will evaluate sponsor fit, sponsor attitude and loyalty more positively as consumers are more likely to associate altruistic motives with the activation campaign. Whereas the opposite can be expected when egoistic motives are inferred.

$H_{3 a-c:}$ Altruistic activation motives positively influence (a) sponsorship fit, (b) sponsor attitude, and $(c)$ sponsor loyalty. $H_{4 \mathrm{a}-\mathrm{c}}:$ Egoistic activation motives negatively influence (a) sponsorship fit, (b) sponsor attitude, and (c) sponsor loyalty. Hal-c3: The positive effects of (a) financial, (b) symbolic, and (c) social benefits on (1) sponsorship fit, (2) sponsor attitude and (3) sponsor loyalty are positively mediated by altruistic campaign motives.

$H_{6 a 1-c 3:}$ The positive effects of (a) financial, $(b)$ symbolic, and (c) social benefits on (1) sponsorship fit, (2) sponsor attitude and (3) sponsor loyalty are negatively mediated by egoistic campaign motives. 
To this point theorizing has emphasized the flow of influence from motive inferencing to outcomes, it is also necessary to consider the differential extent of this influence. The literature on gift giving differentiates between gifts that are financial (in particular money) and gifts that provide a symbolic or other personal value to the recipient and provides evidence that the latter are capable of communicating (e.g., Burgoyne and Routh 1991). In a comparable way, it is expected that activation campaigns incorporating symbolic or social benefits differ conceptually from financially beneficial campaigns. From a theoretical perspective, campaigns with an emphasis on financial benefits correspond with the traditional economic exchange paradigm, whereas symbolic or social benefits lie at the core of the social exchange view (Belk and Coon 1993). In sum, the latter two benefit types should convey a more altruistic underlying motivation. In addition, as the social exchange view entails a generalized rather than a balanced form of reciprocity (Belk and Coon 1993), consumer responses to symbolic and social benefits should be comparatively more positive. $H_{7 a-e}:$ Symbolic and social benefits influence (a) altruistic motives, (b) sponsorship fit, (c) sponsor attitude, and $(d)$ sponsor loyalty more positively, and (e) lower egoistic motives to a stronger extent, compared to financial benefits.

With regard to the impact of sponsorship fit on subsequent outcomes, balance theory suggests that individuals generally strive for congruence (Heider 1958). On this basis, a high fit between a sponsor and a sponsee should elevate sponsor perception to the level of the sponsee. In turn, attempting to level out psychological tensions arising from sponsorships with a poor fit, fans should lower their attitude toward the sponsor and subsequent sponsor outcomes. Given the 
seminal role of sponsorship fit as a mediating concept in explaining sponsorship's impact on sponsor attitude and loyalty, there is ample empirical evidence for the relevance of sponsorship fit in shaping downstream concepts such as attitudes and loyalty (e.g., Pappu and Cornwell 2014; Peloza and Shang 2011; Simmons and Becker-Olsen 2006; Woisetschläger et al. 2017). Thus: $H_{8 \mathrm{a}, \mathrm{b}}$ : Sponsorship fit positively impacts (a) sponsor attitude, and (b) sponsor loyalty.

Fan identification refers to the extent of a fan's emotional attachment and personal commitment with the sports club (Sutton, McDonald, Milne, and Cimperman 1997). Empirical studies show that a high level of fan identification generally affects sponsorship effectiveness in positive ways, evidencing that intended sponsorship outcomes such as higher levels of awareness, a more positive sponsor attitude or higher sponsor loyalty are observable particularly among highly identified fans (e.g., Dalakas and Levin 2005; Madrigal 2001). These findings can be explained by social identity theory (Tajfel and Turner 1985): In light of the support a sponsor provides to the sponsored property, highly identified fans regard a sponsor as a part of their social group, and therefore adopt positive attitudes and behaviors related to the sponsor. Thus, this study suggests positive direct and moderating effects of fan identification on the proposed effect chain stemming from sponsor activation campaigns incorporating fan benefits. $H_{9 \mathrm{a}-\mathrm{e}}$ Fan identification positively impacts (a) altruistic motives, (b) sponsorship fit, (c) sponsor attitude, (d) sponsor loyalty, and negatively impact on (e) egoistic motives. $H_{10 a-j:}$ Fan identification strengthens the positive relationships between (a) financial, (b) symbolic, (c) social benefits and altruistic motives, (d) altruistic motives and sponsorship fit, (e) sponsorship fit and sponsor attitude, and (f) sponsor attitude and sponsor loyalty. Contrastingly, 
fan identification weakens the negative relationships between ( $g$ ) financial, $(h)$ symbolic, $(i)$ social benefits and egoistic motives, and (j) egoistic motives and sponsorship fit.

\section{Stimuli Design, Data Collection and Measures}

To test the proposed hypotheses, four stimuli were designed to manipulate the three experimental conditions (financial, symbolic, and social benefit) and compare their effects with a control condition. Each scenario was formulated as a press release about the initiation of a sponsorship partnership. In each manipulation, the scenarios presented an activation campaign. All three activation conditions were based on a point collection campaign, where the reward (i.e., one of the three benefits) offered could only be received if fans had collected a certain number of points through product purchases from the sponsor. This ensured that all three scenarios represented a commercial sales orientation. Furthermore, this approach allowed for designing experimental stimuli that were identical with regard to their general type, but differed in terms of the nature of benefits addressed.

Two pretests were conducted in order to ensure significant within- and betweenscenario differences with regard to the three benefit dimensions. In pretest 1 , an online questionnaire administered to a sample of 1,000 respondents introduced the initiation of a sponsorship between a major German supermarket corporation and the German Soccer League via a mock press release. In addition to the sponsorship initiation information, the press release contained information about an accompanying activation campaign. Here, each respondent was exposed to one out of 20 different activations (e.g., discounted tickets, a "meet and greet" with a star player) commonly used and identified from the 68 real-world activation campaigns previously mentioned. The selection of a league sponsorship allowed customization of the 
activation benefits offered to the individual respondent's favorite club in the stimulus description. The benefit activation was offered to fans through collection and redemption of loyalty points acquired based on purchases at the supermarket, thus being a sales inducing sponsorship activation. In particular, respondents were offered a loyalty point for every $5 €$ spent; having collected 50 loyalty points, these could be redeemed for one of the 20 activations presented. Pretest 1 reveals that within-stimulus benefit perceptions differ in case of eight out of the 20 activation measures. For example, respondents evaluate the benefit, "discounted tickets," as being predominantly financial $(\mathrm{MV}=4.94, \mathrm{SD}=1.87)$ rather than symbolic $(\mathrm{MV}=4.19$, $\mathrm{SD}=2.03)$ or social $(\mathrm{MV}=4.34, \mathrm{SD}=1.87)$; both differences were significant at $\mathrm{p}<.05$. These eight significantly different benefit activations were considered as candidates for use in the second pretest.

Pretest 2 was conducted in a similar manner. Here, a sample of 564 respondents was exposed to one out of six activation measures selected from the eight measures resulting from pretest 1 (two activations for each of the three benefit dimensions). Confirming the results of pretest 1 , the scenarios "discounted tickets," "fan-photo-event" and "support of a local soccer club" (similar to a "booster club" in the sense that monies support local activities) were evaluated significantly differently regarding the benefit dimensions associated with the scenario (within-scenario difference across types of benefits). Furthermore, the evaluations of benefit dimensions differ significantly between the three scenarios. Finally, the scenarios are similar in terms of intention to participate (no significant differences). Accordingly, the three scenarios mentioned were selected for the main experiment. A fourth scenario was added as control without information about sponsorship activation (see appendix for details). 
The main study was conducted as a representative consumer field study via Respondi, a leading online panel provider in Germany. Quota sampling ensured representativeness in terms of age (18-65), gender, and regional distribution in accordance to the German population. Because of the rolling enrollment to obtain a quota sample, calculating tests of non-response bias are not possible. A total of 4,122 respondents participated in the survey and received a monetary incentive of $.70 €$ for participating. After introductory questions about involvement, the respondents were asked to name their favorite soccer team in the first and second German Bundesliga. Next, identification with their favorite club was measured with three items taken from Wann and Branscombe (1993). To allow separate assessments of the stimuli effects for each team, the data collection focused on fans of the 13 largest teams in the German Bundesliga. A total of 1,356 respondents indicated they were fans of one of these 13 teams. The average age of the respondents was 43.7 years $(\mathrm{SD}=14.2)$, and $45.1 \%$ were female. Each of these respondents was exposed to one of the four different scenarios relating to the main sponsor of the favorite club (nine cases) or a fictitious sponsorship with a retail brand (four cases) when the main sponsor of one of the 13 teams was not suitable for use in a retail activation campaign (e.g., a B2B sponsor). In the scenarios, fans were informed about the nature of the activation campaign (i.e., discounted tickets (financial), fan-photo-event (symbolic) or support of a local soccer club (social)).

After exposure to the manipulations, respondents were asked to indicate their loyalty to the sponsor (adapted from Wang, Po Lo, Chi, and Yang 2004). Next, brand attitude (adapted from Weeks et al. 2008), altruistic and egoistic sponsor motives (Dean 2002; Rifon et al. 2004) and sponsorship fit (Simmons and Becker-Olsen 2006) were evaluated by the respondents. Finally, the respondents had to evaluate their intention to participate in the campaign and the 
financial (adapted from Sheth et al. 1991; Sweeney and Soutar 2001), symbolic (adapted from Kaynak, Salman, and Tatoglu 2008; Sheth et al. 1991), and social benefits (Green and Peloza 2011) received from the sponsorship activation campaign to check the success of the manipulations. Manipulation checks were successful. The scenarios differed with respect to the perceived benefit (all $\mathrm{p}<.01$ ), while the other two benefit types where at the same (lower) level of the respective benefit type (all n.s.). Moreover, their intention to participate in the campaign, as suggested in the pretest, was not significantly different across conditions, thus indicating a similar level of perceived utility.

[Table 1 here]

Composite reliabilities for the reflective constructs exceed .6, the recommended threshold (Bagozzi and Yi 1988). Moreover, we find discriminant validity between the constructs since none of the squared correlation coefficients between any of the constructs exceeds the average variance extracted for a construct (Fornell and Larcker 1981; Table 3).

[Table 2 here]

\section{Results}

Table 3 presents the results of our analysis. In line with $\mathrm{H}_{1 a}$, financial benefit is significantly and positively related to the inference of altruistic motives $\left(\mathrm{H}_{1 \mathrm{a} 1}, \beta=.231 ; \mathrm{p}<.01\right)$. The direct effect on sponsorship fit is only significant at the .1-level $\left(\mathrm{H}_{2 \mathrm{a}}, \beta=.096\right)$, but the mediated effect via altruistic motives $\left(\mathrm{H}_{5 \mathrm{a} 1}\right)$ is significant at $\mathrm{p}<.01$. As proposed by $\mathrm{H}_{1 \mathrm{a} 2}$, egoistic motives are lower, 
when respondents are offered a financial benefit $(\beta=-.262 ; p<.01)$. Furthermore, the effect of financial benefit on sponsor attitude and sponsor loyalty is mediated by altruistic motives, lending support for $\mathrm{H}_{5 \mathrm{a} 2}$ and $\mathrm{H}_{5 \mathrm{a}}$.

Symbolic benefit shows positive effects on altruistic motives $\left(\mathrm{H}_{1 \mathrm{~b} 1}, \beta=.349 ; \mathrm{p}<.01\right)$ and lowers the inference of egoistic motives $\left(\mathrm{H}_{1 \mathrm{~b} 2}, \beta=-.554 ; \mathrm{p}<.01\right)$. A direct relationship to sponsorship fit cannot be observed $\left(\mathrm{H}_{2 b}\right)$, but an indirect effect via altruistic motives exists, thereby giving support for $\mathrm{H}_{5 b 1}$. Mediation analysis shows that the effect of symbolic benefit on sponsor attitude and sponsor loyalty is fully mediated by altruistic motives. This finding gives support to $\mathrm{H}_{5 b 2}$ and $\mathrm{H}_{5 b 3}$.

Social benefit is also related to altruistic motives $\left(\mathrm{H}_{1 \mathrm{cl}}, \beta=.313 ; \mathrm{p}<.01\right)$ and weakens the inference of egoistic motives $\left(\mathrm{H}_{1 \mathrm{c} 2}, \beta=-.551 ; \mathrm{p}<.01\right)$. The effect of social benefit on sponsorship fit, sponsor attitude, and sponsor loyalty is fully mediated by altruistic motives, supporting $\mathrm{H}_{5 \mathrm{cl}}$, $\mathrm{H}_{5 \mathrm{c} 2}$, and $\mathrm{H}_{5 \mathrm{c} 3}$. Altruistic motives are significantly and positively related to sponsorship fit $\left(\mathrm{H}_{3 \mathrm{a}}\right.$, $\beta=.516 ; \mathrm{p}<.01)$, sponsor attitude $\left(\mathrm{H}_{3 \mathrm{~b}}, \beta=.315 ; \mathrm{p}<.01\right)$, and sponsor loyalty $\left(\mathrm{H}_{3 \mathrm{c}}, \beta=.200 ; \mathrm{p}<.01\right)$.

Contrary to $\mathrm{H}_{4 \mathrm{a}}$ and $\mathrm{H}_{4 \mathrm{~b}}$, no significant influence of egoistic motive attributions on sponsorship fit and sponsorship attitude is observed. The effect of egoistic motives on sponsor loyalty is in the proposed direction ( $\beta=-.039)$ but is only significant at the .10 level, therefore providing limited support for $\mathrm{H}_{4 \mathrm{c}}$. No mediation exists between of the benefit types via egoistic motives on sponsor outcomes. Hence $\mathrm{H}_{6 a 1-c 3}$ are rejected. As proposed by $\mathrm{H}_{7 \mathrm{e}}$, the effects of symbolic and social benefits on egoistic motive attributions are more pronounced than the effect of financial benefit (both significantly different at $\mathrm{p}<.01$ ). Further, the difference in total effects of symbolic benefit vs. financial benefit on sponsor loyalty is in the expected direction, but is only significant at the 10 level, providing only limited support for $\mathrm{H}_{7 \mathrm{~d}}$. All other comparisons of 
effect sizes are non-significant. In line with $\mathrm{H}_{8 \mathrm{a}}$ and $\mathrm{H}_{8 \mathrm{~b}}$, sponsorship fit shows positive effects on sponsor attitude and sponsor loyalty. The effect on sponsor loyalty is partially mediated by sponsor attitude.

As proposed by $\mathrm{H}_{9 \mathrm{a}}$, fan identification is significantly and positively related to the inference of altruistic motives $(\beta=.223 ; \mathrm{p}<.01)$. However, it is unrelated to egoistic motives, leading to the rejection of $\mathrm{H}_{9 \mathrm{e}}$. Moreover, sponsorship fit $\left(\mathrm{H}_{9 \mathrm{~b}}, \beta=.062 ; \mathrm{p}<.01\right)$ and sponsor loyalty $\left(\mathrm{H}_{9 \mathrm{~d}}, \beta=.109 ; \mathrm{p}<.01\right)$ are higher with increasing fan identification. The direct effect of fan identification on sponsor attitude is non-significant. Hence, $\mathrm{H}_{9 \mathrm{c}}$ is rejected. As hypothesized, several moderating effects of fan identification are observed. In line with the proposed hypotheses, fan identification amplifies the effects of symbolic benefit on the inference of altruistic motives $\left(\mathrm{H}_{10 \mathrm{~b}}, \beta=.033 ; \mathrm{p}<.01\right)$, strengthens the link between altruistic motives and sponsorship fit $\left(\mathrm{H}_{10 \mathrm{~d}}, \beta=.024 ; \mathrm{p}<.01\right)$, and the effects of sponsorship fit on sponsor attitude $\left(\mathrm{H}_{10 \mathrm{e}}\right.$, $\beta=.021 ; \mathrm{p}<.01)$ and sponsor loyalty $\left(\mathrm{H}_{10 \mathrm{f}}, \beta=.026 ; \mathrm{p}<.01\right)$. In line with $\mathrm{H}_{10 \mathrm{~h}}$, fan identification decreases the inference of egoistic motives, when symbolic benefit is offered to fans $(\beta=-.027$; $\mathrm{p}<.05)$. Contrary to $\mathrm{H}_{10 \mathrm{i}}$, social benefit is associated with egoistic motives at higher levels of fan identification $(\beta=.039 ; \mathrm{p}<.01)$. All other hypothesized moderating effects of fan identification are non-significant.

[Table 3 here]

The focal model was compared to an alternative model in which sponsorship fit is an antecedent of inferred sponsor motives. All fit indices and Akaike's information criteria (AIC, BIC, ssBIC) were compared according to Rust, Lee, and Valente (1995), with the result that the 
alternate model $(\mathrm{CFI}=.975 ; \mathrm{TLI}=.967 ; \mathrm{RMSEA}=.038 ; \mathrm{SRMR}=.057 ; \mathrm{AIC}=60,728.802$;

$\mathrm{BIC}=61,510.647 ; \mathrm{ssBIC}=61,034.160)$ is inferior to the focal model $(\mathrm{CFI}=.976 ; \mathrm{TLI}=.968$;

RMSEA=.037; SRMR=.055; $\mathrm{AIC}=60,707.082 ; \mathrm{BIC}=61,494.139 ; \mathrm{ssBIC}=61,014.475)$.

Moreover, the results of a multi-group structural equation model show that the reported effects are consistent for fictitious and existing retail sponsor partnerships.

\section{Discussion}

This research contributes to the marketing literature by developing a conceptual framework of campaign-related factors in sponsorship activation. The empirical research focuses on different benefits offered to fans of the sponsored property as part of sales-oriented activation campaigns and their consequences on motive inferences, sponsorship fit, and attitudinal and behavioral sponsor outcomes.

The first important finding is that sponsorships are successful when recognizable fanbenefits are part of the activation strategy. This is remarkable, since sales-oriented activation campaigns incorporate sponsor self-interest by design. Nonetheless, the empirical work finds positive indirect effects of the activation strategies, irrespective of their content, on sponsor outcomes. If fans see financial, symbolic or social benefits in sponsorship activation campaigns, their attitudes towards the sponsor and their intention to buy products from the sponsor are positively affected.

Second, and in line with attribution theory, the influence of fan-benefits on attitudinal and behavioral intentions towards the sponsor is mediated by the inference of altruistic motives of the sponsor. Consumers appreciate personal benefits resulting from sponsorship activation and see the campaign in a generally more positive light, as both altruistic and egoistic motivations are 
perceived more favorably when any kind of benefit is offered. As might be expected, mediation takes place only via altruistic motives not via egoistic motives. This finding could be interpreted as higher levels of sponsor altruism being associated with higher levels of consumer benefit while higher levels of sponsor egoism do not correspond to consumers being worse off in any of the alternatives. It thus seems that sales-driven sponsorship campaigns are accepted as long as a certain benefit for fans is incorporated, ensuring a reciprocal relationship between sponsor and fans. In addition, the two motives are antagonistic, meaning that higher levels of perceived egoism are already reflected in lower levels of perceived altruism. Another explanation for this finding could be rooted in the setting of the empirical study. Recent research by Woisetschläger et al. (2017) concludes that the development of affective motives might be particularly relevant in sports with a higher extent of commercialization, such as European soccer. Therefore, within a highly commercialized context, any benefit that offsets commercialization perceptions would be positively regarded.

Third, the results show that - although all benefit types result in improvements of sponsorship outcomes - symbolic and social benefits show slightly superior effects relative to financial benefit in lowering inference of egoistic motives and improving loyalty towards sponsors. An activation offering financial benefit is interpreted as exchange oriented by consumers; whereas the symbolic and social benefit here communicate less calculative motives. This is in line with findings from the gift-giving literature, which indicate that the type of gift provides a communication cue regarding respect and compatibility between givers and receivers (Belk and Coon 1993; Burgoyne and Routh 1991).

Fourth, with higher levels of fan identification, symbolic benefits are more strongly (weakly) associated with altruistic (egoistic) motives of the sponsor. These findings are in line 
with social identification theory, as symbolic contributions of sponsors are perceived as signal of the sponsor's identification with the sponsored property. In contrast to these results, no such moderating effect can be observed for financial benefits, and further, egoistic motives are seen as more pronounced with increasing levels of fan identification.

Fifth, this research offers additional implications for theory and study design. This work runs counter to some empirical work regarding the location of fit in a conceptual frame. Fit is an established construct and is typically antecedent to motives for the sponsorship. In this work, because the manipulations of activation benefits precede the measure of motives and fit, one sees the implications of these manipulations and prior measures on the fit construct. The alternative model confirms the location of fit based on these study materials as a consequence of activation benefits and motive inferences. Thus, this study responds to calls for comparative analyses regarding the role of alternative communication measures in shaping sponsorship fit (Mazodier and Quester 2014). Clearly, sales-oriented activation campaigns can alter perceptions of fit.

\section{Managerial implications}

A key implication for sponsorship management is that the goodwill associated with sponsorship can be enhanced by sponsorship activation comprising fan benefits. Looking at high-profile sports today, many sponsors hold brand awareness as the dominant communication goal and strive primarily for media exposure. In many instances, however, sponsor investments made are ineffective because of clutter and fan reluctance to accept commercial stimuli. In order to preserve the inherent goodwill of sponsoring and at the same time support sales goals, brands need to scrutinize how their sponsorship can be activated. While the empirical results of this research show that providing fan benefits results in better sponsorship outcomes irrespective of 
the nature of the benefits provided, symbolic and social benefits are more effective than financial benefits in affecting reactions to sponsorship. The high share of campaigns with a strong emphasis on financial benefits as found in the preliminary study, suggests preference for financial instruments, likely because giving coupons, rebates, and discounts is easy and provides tracking information. Admittedly, symbolic and social value benefits may be more difficult to design because they require a thorough understanding of the fans, the sponsored property, and its environment but this additional effort may be worthwhile.

Another approach could be to offer different fan benefits in parallel, and rely on selfselection by fans from varied activation opportunities. For example, one might expect that fans with higher levels of identification with the team would respond more readily to activations having symbolic benefits. Highly identified fans, especially those spending on season passes, may need a message of appreciation. Other individual traits such as financial conservatism or community orientation may lead to the selection of financial or social benefits respectively.

\section{Limitations and further research}

This research has limitations that suggest avenues for future research. In this study design, the control condition had no filler or alternative non-activation content. Therefore, while unlikely, the simple fact of extended engagement during exposure conditions having activation messages may have resulted in more favorable attitudes. Future research should consider a control condition with filler materials of a similar length as those in the experimental conditions of interest and with content typical of the study context.

Another limitation of the current research is the use of scenarios in exposing participants to the benefit activation manipulations. While scenarios might be considered a strong test of the 
potential of the activations employed due to being only text based (visual, auditory and animated exposures could be stronger manipulations), further testing should include mock or actual activations to gain ecological validity in alternative sponsorship contexts. Further testing might consider the source of these benefit activations (e.g., the brand as sponsor, the sport as sponsee, the charity as beneficiary).

To support future research Figure 1 presents a general model, some of which has not been tested in the current empirical work. Activation campaigns might work in certain environments and not in others leading to the conclusion that standardization of sponsorship activation might not lead to the best outcomes. Therefore, future research should examine the environmental conditions shaping fan reactions to sponsorship activation campaigns. For instance, sales-oriented activation campaigns may be well accepted in high profile professional sports, but encounter resistance in youth sports. Future research should also consider varied financial values. While the financial value offered here was acceptable and produced positive outcomes, incentives too high might evoke stronger egoistical concerns and incentives too low might be perceived as trivial. Other activation designs worth of consideration would be mixed values (e.g., financial and emotional) or previously mentioned choice designs where an individual might choose between a financial incentive and a symbolic or social one. 


\section{References}

Activative (2017). Activative Annual 2016/17 - Sponsorship activation, partnership leverage, \& sports marketing, http://www.activative.co.uk/wp-content/uploads/2017/01/ActivativeAnnual-2016-2017-Interactive1.pdf. Accessed 26/09/2017.

Bagozzi, R. P., \& Yi, Y. (1988). On the evaluation of structural equation models. Journal of the Academy of Marketing Science, 16(1), 74-94.

Becker-Olsen, K. L., \& Simmons, C. J. (2002). When do social sponsorships enhance or dilute equity? Fit, message source, and the persistence of effects. Advances in Consumer Research, 29, 287-289.

Bee, C., \& Dalakas, V. (2015). Rivalries and sponsor affiliation: Examining the effects of social identity and argument strength on responses to sponsorship-related advertising messages. Journal of Marketing Communications, 21(6), 408-424.

Belk, R. W., \& Coon, G. S. (1993). Gift giving as agapic love: An alternative to the exchange paradigm based on dating experiences. Journal of Consumer Research, 20(3), 393-417.

Blau, P. M. (1964). Exchange and power in social life. New York.

Breuer, C., \& Rumpf, C. (2015). The impact of color and animation on sports viewers' attention to televised sponsorship signage. Journal of Sport Management, 29(2), 170-183.

Burgoyne, C. B., \& Routh, D. A. (1991). Constraints on the use of money as a gift at Christmas: the role of status and intimacy. Journal of Economic Psychology, 12(1), 47-69.

Chandon, P., Wansink, B., \& Laurent, G. (2000). A benefit congruency framework of sales promotion effectiveness. Journal of Marketing, 64(4), 65-81. 
Coppetti, C., Wentzel, W., Tomczak, T., \& Henkel, S. (2009). Improving incongruent sponsorships through articulation of the sponsorship and audience participation. Journal of Marketing Communications, 15(1), 17-34.

Cornwell, T. B., \& Relyea, G. E. (2000). Understanding long-term effects of sports sponsorship: Role of experience, involvement, enthusiasm and clutter. International Journal of Sports Marketing and Sponsorship, 2(2), 39-55.

Cornwell, T. B., Weeks, C. S., \& Roy, D. P. (2005). Sponsorship-linked marketing: opening the black box. Journal of Advertising, 34(2), 21-42.

Cornwell, T. B., Humphreys, M. S., Maguire, A. M., Weeks, C. S., \& Tellegen, C. L. (2006). Sponsorship-linked marketing: The role of articulation in memory. Journal of Consumer Research, 33(3), 312-321.

Crompton, J. L. (2014). Potential negative outcomes from sponsorship for a sport property. Managing Leisure, 19(6), 420-441.

Dalakas, V., \& Levin, A. M. (2005). The balance theory domino: How sponsorships may elicit negative consumer attitudes. ACR North American Advances, 32, 91-97.

Dean, D. H. (2002). Associating the corporation with a charitable event through sponsorship: Measuring the effects on corporate community relations. Journal of Advertising, 31(4), $77-87$.

Deitz, G. D., Myers, S. W., \& Stafford, M. R. (2012). Understanding consumer response to sponsorship information: A resource-matching approach. Psychology \& Marketing, 29(4), 226-239. 
Donlan, L., \& Crowther, P. (2014). Leveraging sponsorship to achieve consumer relationship objectives through the creation of 'marketing spaces': An exploratory study. Journal of Marketing Communications, 20(4), 291-306.

Du, S., Bhattacharya, C. B., \& Sen, S. (2010). Maximizing business returns to corporate social responsibility (CSR): The role of CSR communication. International Journal of Management Reviews, 12(1), 8-19.

Ellen, P. S., Webb, D. J., \& Mohr, L. A. (2006). Building corporate associations: Consumer attributions for corporate socially responsible programs. Journal of the Academy of Marketing Science, 34(2), 147-157.

Farrelly, F., \& Quester, P. G. (2003). What drives renewal of sponsorship principal/agent relationships?. Journal of Advertising Research, 43(4), 353-360.

Fornell, C., \& Larcker, D. F. (1981). Evaluating structural equation models with unobservable variables and measurement error. Journal of Marketing Research, 18(1), 39-50.

Glindmeier, T. (2011). Alarmstufe Rot beim FC St. Pauli. http://www.spiegel.de/sport/fussball/fans-vs-praesidium-alarmstufe-rot-beim-fc-st-paulia-739586.html. Accessed 26/10/2017.

Green, T., \& Peloza, J. (2011). How does corporate social responsibility create value for consumers? Journal of Consumer Marketing, 28(1), 48-56.

Grohs, R., Reisinger, H., \& Woisetschläger, D. M. (2015). Attenuation of negative sponsorship effects in the context of rival sports teams' fans. European Journal of Marketing, 49(11/12), 1880-1901.

Gouldner, A. W. (1960). The norm of reciprocity: A preliminary statement. American Sociological Review, 25(2),161-178. 
Gwinner, K. (1997). A model of image creation and image transfer in event sponsorship. International Marketing Review, 14(3), 145-158.

Heider, F. (1958). The psychology of interpersonal relationships. New York.

Hypovereinsbank (2017). Bayern Munich financial products, https://about.hypovereinsbank.de/en/sport/fc-bayern-muenchen/. Accessed 26/09/2017.

International Event Group (2016). Average activation-to-fee ratio passes two-to-one mark for first time. http://www.sponsorship.com/iegsr/2016/12/19/Average-Activation-To-FeeRatio-Passes-Two-To-One-.aspx. Accessed 03/10/2017.

International Event Group (2018). What sponsors want \& where dollars will go in 2018. http://www.sponsorship.com/IEG/files/f3/f3cfac41-2983-49be-8df6-3546345e27de.pdf. Accessed 08/02/2018.

Kaynak, E., Salman, G. G., \& Tatoglu, E. (2008). An integrative framework linking brand associations and brand loyalty in professional sports. Journal of Brand Management, $15(5), 336-357$.

Kim, Y., Lee, H. W., Magnusen, M. J., \& Kim, M. (2015). Factors influencing sponsorship effectiveness: A meta-analytic review and research synthesis. Journal of Sport Management, 29(4), 408-425.

Kuzma, J. R., Shanklin, W. L., \& McCally, J. F. (1993). Number one principle for sporting events seeking corporate sponsors: Meet benefactor's objectives. Sport Marketing Quarterly, 2(3), 27-32.

Madrigal, R. (2001). Social identity effects in a belief-attitude-intentions hierarchy: Implications for corporate sponsorship. Psychology \& Marketing, 18(2), 145-165. 
Mazodier, M., \& Quester, P. (2014). The role of sponsorship fit for changing brand affect: A latent growth modeling approach. International Journal of Research in Marketing, 31(1), $16-29$.

McDaniel, S. R., \& Chalip, L. (2002). Effects of commercialism and nationalism on enjoyment of an event telecast: Lessons from the Atlanta Olympics. European Sport Management Quarterly, 2(1), 3-22.

Meenaghan, T. (1998). Current developments \& future directions in sponsorship. International Journal of Advertising, 17(1), 3-28.

Meenaghan, T. (2001). Understanding sponsorship effects. Psychology \& Marketing, 18(2), 95122.

Na, J., \& Kim, J. (2013). Does 'articulation' matter in sponsorship? The type of articulation and the degree of congruence as determinants of corporate sponsorship effects. Asian Journal of Communication, 23(3), 268-283.

Palmatier, R. W., Jarvis, C. B., Bechkoff, J. R., \& Kardes, F. R. (2009). The role of customer gratitude in relationship marketing. Journal of Marketing, 73(5), 1-18.

Pappu, R., \& Cornwell, T. B. (2014). Corporate sponsorship as an image platform: understanding the roles of relationship fit and sponsor-sponsee similarity. Journal of the Academy of Marketing Science, 42(5), 490-510.

Peloza, J., \& Shang, J. (2011). How can corporate social responsibility activities create value for stakeholders? A systematic review. Journal of the Academy of Marketing Science, 39(1), $117-135$. 
Reeder, G. D., Vonk, R., Ronk, M. J., Ham, J., \& Lawrence, M. (2004). Dispositional attribution: Multiple inferences about motive-related traits. Journal of Personality and Social Psychology, 86(4), 530-544.

Rifon, N. J., Choi, S. M., Trimble, C. S., \& Li, H. (2004). Congruence effects in sponsorship: The mediating role of sponsor credibility and consumer attributions of sponsor motive. Journal of Advertising, 33(1), 30-42.

Roy, D. P., \& Cornwell, T. B. (2004). The effects of consumer knowledge on responses to event sponsorships. Psychology \& Marketing, 21(3), 185-207.

Rust, R. T., Lee, C., \& Valente, E. (1995). Comparing covariance structure models: A general methodology. International Journal of Research in Marketing, 12(4), 279-291.

Sheth, J. N., Newman, B. I., \& Gross, B. L. (1991). Why we buy what we buy: A theory of consumption values. Journal of Business Research, 22(2), 159-170.

Simmons, C. J., \& Becker-Olsen, K. L. (2006). Achieving marketing objectives through social sponsorships. Journal of Marketing, 70(4), 154-169.

Speed, R., \& Thompson, P. (2000). Determinants of sports sponsorship response. Journal of the Academy of Marketing Science, 28(2), 226-238.

Sponsors (2017): Bundesliga 2017/18: Übersicht TV-relevante Sponsoren und Werbemittel. https://www.sponsors.de/sites/default/files/werbemittel_bundesliga.pdf, accessed 26/09/2017.

Sutton, W. A., McDonald, M. A., Milne, G. R., \& Cimperman, J. (1997). Creating and fostering fan identification in professional sports. Sport Marketing Quarterly, 6(1), 15-22.

Sweeney, J. C., \& Soutar, G. N. (2001). Consumer perceived value: The development of a multiple item scale. Journal of Retailing, 77(2), 203-220. 
Tajfel, H. \& Turner, J. C. (1985). The social identity theory of intergroup behavior. In: Worchel S., Austin WG (Ed). Psychology of Intergroup Behavior, Vol. 2. Chicago (IL): NealsonHall, 7-24.

Wang, Y., Po Lo, H., Chi, R., \& Yang, Y. (2004). An integrated framework for customer value and customer-relationship-management performance: a customer-based perspective from China. Managing Service Quality: An International Journal, 14(2/3), 169-182.

Wann, D. L., \& Branscombe, N. R. (1993). Sports fans: Measuring degree of identification with their team. International Journal of Sport Psychology, 24(1), 1-17.

Weeks, C. S., Cornwell, T. B., \& Drennan, J. C. (2008). Leveraging sponsorships on the internet: activation, congruence, and articulation. Psychology \& Marketing, 25(7), 637-654.

Western Union (2017). Western Union becomes money transfer partner and shirt sleeve sponsor of Liverpool Football Club, http://ir.westernunion.com/news/archived-pressreleases/press-release-details/2017/Western-Union-Becomes-Money-Transfer-Partnerand-Shirt-Sleeve-Sponsor-of-Liverpool-Football-Club/default.aspx, accessed 26/09/2017.

Woisetschläger, D. M., Backhaus, C., \& Cornwell, T. B. (2017). Inferring corporate motives: How deal characteristics shape sponsorship perceptions. Journal of Marketing, 81(5), $121-141$.

Woisetschläger, D. M., Backhaus, C., Dreisbach, J., \& Schnöring, M. (2014). Sponsoringstudie 2014: Die Sponsoringpotenziale in der Fußball-Bundesliga. Working paper of the Institute of Automotive Management and Industrial Production. 
Figure 1: Conceptual Model of Sponsorship Activation Effects*

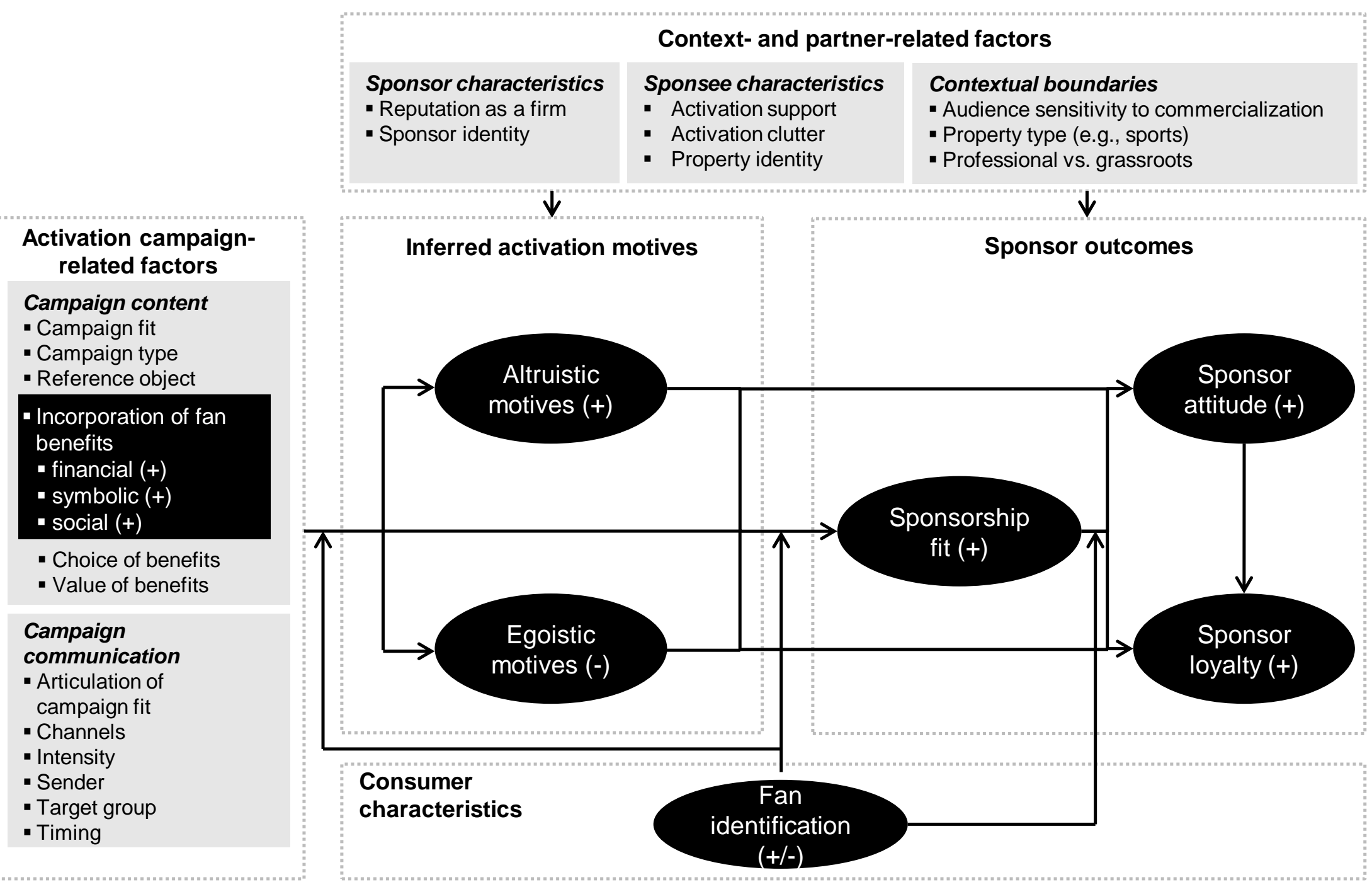

*Empirically examined aspects of the model are indicated in black 
Table 1: Measurement of Latent Constructs and Results of Confirmatory Factor Analysis

\begin{tabular}{|c|c|c|c|}
\hline Construct & $\begin{array}{l}\text { Factor } \\
\text { Loading }\end{array}$ & $\begin{array}{l}\text { Composite } \\
\text { Reliability }\end{array}$ & $\begin{array}{l}\text { Average } \\
\text { Variance } \\
\text { Extracted }\end{array}$ \\
\hline Sponsor loyalty & & .935 & .828 \\
\hline I would consider myself loyal to [brand] in the future. & .772 & & \\
\hline [Brand] is always my first choice. & .974 & & \\
\hline $\begin{array}{l}\text { Instead of buying from somebody else, I will always buy from } \\
\text { [brand]. }\end{array}$ & .969 & & \\
\hline Sponsor attitude & & .980 & .942 \\
\hline $\begin{array}{l}\text { Please indicate your overall opinion about sponsor [brand]: } \\
\text { negative ... positive } \\
\text { bad ... good } \\
\text { favorable ... unfavorable }\end{array}$ & $\begin{array}{l}.970 \\
.984 \\
.957\end{array}$ & & \\
\hline $\begin{array}{l}\text { Sponsorship fit } \\
\text { Please evaluate the connection between [brand] and [club]: }\end{array}$ & & 0.965 & 0.901 \\
\hline $\begin{array}{l}\text { Dissimilar ... similar } \\
\text { Not complementary ... complementary } \\
\text { Low fit ... high fit }\end{array}$ & $\begin{array}{l}.929 \\
.956 \\
.962\end{array}$ & & \\
\hline Altruistic motives & & 0.941 & 0.842 \\
\hline $\begin{array}{l}\text { Please indicate how much you agree with the following statements. } \\
\text { [Sponsor] initiated this campaign to ... }\end{array}$ & & & \\
\hline $\begin{array}{l}\ldots \text { because it feels committed to its customers and the soccer fans. } \\
\ldots \text { because it wants to give something back to its customers and the } \\
\text { soccer fans. }\end{array}$ & $\begin{array}{l}.891 \\
.941\end{array}$ & & \\
\hline $\begin{array}{l}\text {.. because it wants to support its customers and the soccer fans. } \\
\text { Egoistic motives }\end{array}$ & .920 & 0.928 & 0.811 \\
\hline $\begin{array}{l}\text { Please indicate how much you agree with the following statements. } \\
\text { [Sponsor] initiated this campaign to ... } \\
\ldots \text { act in its own self-interest. } \\
\ldots \text { act to benefit itself. } \\
\ldots \text { for selfish reasons. }\end{array}$ & $\begin{array}{l}.930 \\
.930 \\
.839\end{array}$ & & \\
\hline Fan identification & & 0.955 & 0.877 \\
\hline I see myself as a very strong fan of [team]. & .959 & & \\
\hline My friends see me as a very strong fan of [team]. & .946 & & \\
\hline It is very important for me to be a fan of [team]. & .904 & & \\
\hline
\end{tabular}


Table 2: Correlations

\begin{tabular}{|c|c|c|c|c|c|c|c|c|}
\hline & $(1)$ & (2) & (3) & (4) & $(5)$ & (6) & $(7)$ & $(8)$ \\
\hline (1) Sponsor loyalty & 1 & & & & & & & \\
\hline (2) Sponsor attitude & $.594 * * *$ & 1 & & & & & & \\
\hline (3) Sponsorship fit & $.488 * * *$ & $.745 * * *$ & 1 & & & & & \\
\hline (4) Altruistic motives & $.543 * * *$ & $.656 * * *$ & $.570 * * *$ & 1 & & & & \\
\hline (5) Egoistic motives & $-.199 * * *$ & $-.210 * * *$ & $-.177 * * *$ & $-.328 * * *$ & 1 & & & \\
\hline (6) Fan identification & $.230 * * *$ & $.162 * * *$ & $.173 * * *$ & $.206 * * *$ & $.007^{\text {n.s. }}$ & 1 & & \\
\hline (7) Financial benefit & $.072 * *$ & $.111 * * *$ & $.083 * * *$ & $.106^{* * *}$ & $-.103 * * *$ & $.032^{\text {n.s. }}$ & 1 & \\
\hline (8) Symbolic benefit & $.105 * * *$ & $.111 * * *$ & $.058 *$ & $.138 * * *$ & $-.220 * * *$ & $.011^{\text {n.s. }}$ & --- & 1 \\
\hline (9) Social benefit & $.042^{\text {n.s. }}$ & $.122 * * *$ & $.091 * * *$ & $.135^{* * *}$ & $-239 * * *$ & $-.049^{\text {n.s. }}$ & --- & --- \\
\hline
\end{tabular}


Table 3: Results

\begin{tabular}{|c|c|c|}
\hline & Std. Coefficient & $\mathrm{R}^{2}$ \\
\hline Sponsor loyalty & & $45.7 \%$ \\
\hline Sponsor attitude $(+)$ & $.328 * * *$ & \\
\hline Sponsorship fit $(+)$ & $.140 * * *$ & \\
\hline Altruistic motives $(+)$ & $.200 * * *$ & \\
\hline Egoistic motives (-) & $-.039 *$ & \\
\hline Fan identification $(+)$ & $.109 * * *$ & \\
\hline Sponsorship fit*fan identification $(+)$ & $.026 * * *$ & \\
\hline Sponsor attitude & & $64.2 \%$ \\
\hline Sponsorship fit $(+)$ & $.582 * * *$ & \\
\hline Altruistic motives $(+)$ & $.315 * * *$ & \\
\hline Egoistic motives (-) & $.007^{\text {n.s. }}$ & \\
\hline Fan identification $(+)$ & $-.003^{\text {n.s. }}$ & \\
\hline Sponsorship fit*fan identification $(+)$ & $.021 * * *$ & \\
\hline Sponsorship fit & & $47.1 \%$ \\
\hline Altruistic motives $(+)$ & $.516 * * *$ & \\
\hline Egoistic motives (-) & $-.002^{\text {n.s. }}$ & \\
\hline Fan identification $(+)$ & $.062 * * *$ & \\
\hline Altruistic motives*fan identification (+) & $.024 * * *$ & \\
\hline Egoistic motives*fan identification $(-)$ & $-.004^{\text {n.s. }}$ & \\
\hline Financial benefit $(+)$ & $.096 *$ & \\
\hline Symbolic benefit (+) & $.024^{\text {n.s. }}$ & \\
\hline Social benefit $(+)$ & $.058^{\text {n.s. }}$ & \\
\hline Altruistic motives & & $9.2 \%$ \\
\hline Fan identification $(+)$ & $.223 * * *$ & \\
\hline Financial benefit $(+)$ & $.231 * * *$ & \\
\hline Symbolic benefit $(+)$ & $.349 * * *$ & \\
\hline Social benefit $(+)$ & $.313^{* * *}$ & \\
\hline Financial benefit*fan identification $(+)$ & $-.019^{\text {n.s. }}$ & \\
\hline Symbolic benefit*fan identification (+) & $.033 * * *$ & \\
\hline Social benefit*fan identification $(+)$ & $-.013^{\text {n.s. }}$ & \\
\hline Egoistic motives & & $7.5 \%$ \\
\hline Fan identification $(-)$ & $-.013^{\text {n.s. }}$ & \\
\hline Financial benefit (-) & $-.262 * * *$ & \\
\hline Symbolic benefit (-) & $-.554 * * *$ & \\
\hline Social benefit $(-)$ & $-.551 * * *$ & \\
\hline Financial benefit*fan identification (-) & $-.012^{\text {n.s. }}$ & \\
\hline Symbolic benefit*fan identification $(-)$ & $-.027 * *$ & \\
\hline Social benefit*fan identification (-) & $.039 * * * *$ & \\
\hline
\end{tabular}

Global fit indices: CFI .976; TLI .968; RMSEA .037; SRMR .055 | The model controls for the effects of different sponsor partnerships. $\mathrm{N}=1,356$; Significant results (two-tailed) at $p<.01(* * *)$ and $p<.05(* *)$ are in bold, results $(p<.10, *)$ are in italics, nonsignificant effects (n.s.) are in normal font. 


\section{Appendix: Scenarios}

\section{Introduction}

Sponsoring partnership between [brand] and [club]

[Brand] and [club] are happy to announce a three-year sponsor partnership.

As part of the sponsoring partnership with [club], [brand] launches the following campaign for its customers, making shopping at [brand] even more rewarding. Customers of [brand] can now be part of a unique sales promotion and receive attractive soccer-related rewards. And here is how it works:

\section{Scenario 1: Discounted tickets (financial benefit)}

Until [Date] you receive a loyalty point for every $5 €$ you spend at [brand]. For $\mathbf{5 0}$ loyalty points, you can purchase a ticket of your choice for a match of [club] in the coming season [date] with a one-time discount of $10 €$ on the regular ticket price (the number of tickets is limited for certain matches). The bonus booklet for this campaign is now available at every participating [brand] dealer.

\section{Scenario 2: Fan-photo-event (symbolic benefit)}

Until [Date] you receive a loyalty point for every $5 €$ you spend at [brand]. For 50 loyalty points, you can be part of a fan-photo-shooting in your local [brand] store on one of five dates, and show your commitment to [club]. A mosaic with the photos of all participating fans will be created and installed near the stadium of [club] on a permanent basis. As a memento of the event, you will also receive a print of your photo. The bonus booklet for this campaign is now available at every participating [brand] dealer.

\section{Scenario 3: Support of a local soccer club (social benefit)}

Until [Date] you receive a loyalty point for every $5 €$ you spend at [brand]. For $\mathbf{5 0}$ loyalty points you can support the [club]'s campaign ,,soccer without frontiers.“ [Brand] contributes financially to this campaign, which helps local soccer clubs in your neighborhood to renovate and improve sporting grounds and facilities. For each completed booklet, $10 €$ will be donated to a local soccer club. [Brand] and [club] select the supported clubs jointly. The bonus booklet for this campaign is now available at every participating [brand] dealer. 